\title{
Effect of Multistage Thermal Cracking on Permeability of Granite
}

\author{
Zi-jun Feng $\mathbb{D}^{1,2}$ Yang-sheng Zhao, ${ }^{1,2}$ Peng Zhao, ${ }^{1,2}$ and Zhi-jun Wan $\mathbb{D}^{3}$ \\ ${ }^{1}$ Department of Mining Engineering, Taiyuan University of Technology, Taiyuan, Shanxi 030024, China \\ ${ }^{2}$ Key Laboratory of In-Situ Property-Improving Mining of Ministry of Education, Taiyuan University of Technology, Taiyuan, \\ Shanxi 030024, China \\ ${ }^{3}$ School of Mines, China University of Mining Technology, Xuzhou, Jiangsu 221116, China \\ Correspondence should be addressed to Zi-jun Feng; fengzijun@tyut.edu.cn
}

Received 14 November 2019; Accepted 12 February 2020; Published 9 March 2020

Academic Editor: Hongtao Zhu

Copyright (c) $2020 \mathrm{Zi}$-jun Feng et al. This is an open access article distributed under the Creative Commons Attribution License, which permits unrestricted use, distribution, and reproduction in any medium, provided the original work is properly cited.

\begin{abstract}
Experiments on thermal cracking in granite sample were conducted through acoustic emission monitoring, and changes in permeability were concomitantly studied using $600^{\circ} \mathrm{C} 20 \mathrm{MN}$ servo-controlled triaxial rock mechanics testing machine. Two granite samples, $200 \mathrm{~mm}$ in diameter and $400 \mathrm{~mm}$ long, from Shandong, China, were selected for these experiments. Both samples were heated up to $500^{\circ} \mathrm{C}$ at ambient pressure. We find that thermal cracking of large-scaled granite is discontinuous and exhibits multiple stages with temperature. In addition, the permeability exhibits the following characteristics: (a) it neither increases nor decreases monotonously with the temperature rising and it exhibits multipeak due to the multistage thermal cracking; (b) the temperature of permeability peak lags behind that of the drastic acoustic emission activities. Both AE counts and permeability dramatically increased after $300^{\circ} \mathrm{C}$, which indicated serious thermal cracking occurred after $300^{\circ} \mathrm{C}$. Permeability ratio is approximately linear with the ratio of $\mathrm{AE}$ cumulative counts. The results will be helpful for understanding the mechanism of geothermal reservoir construction and long-term evaluation of safety for nuclear waste geological disposal.
\end{abstract}

\section{Introduction}

Temperature change induced by heating or cooling in rock will produce thermal cracking. Thermal cracking is closely related to many engineering such as heavy oil mining, underground coal gasification, nuclear waste disposal, and geothermal energy extraction. In order to enhance heavy oil recovery, high temperature vapor injection or combustion technology is often applied to reduce oil viscosity and increase permeability of surrounding rock. The permeability can augment by heating which induces thermal cracking in surrounding rock [1-3]. The same process also happens in underground coal gasification $[4,5]$. Disposal reservoir will be heated by nuclear waste and thermal cracking will occur in the engineering of nuclear waste disposal $[6,7]$.

Geothermal resources, as a kind of sustainable and green energy, have attracted worldwide attention. Hot dry rock (HDR) geothermal energy is potential renewable and alternative source energy due to high-quality huge reserves and clean producing electricity. HDR geothermal energy is mainly deep-buried in granite bodies called reservoirs. Granite is formed after rock-magma shrinks during uplifting and cooling process, and this is a clear thermal cracking phenomenon. Water is injected into geothermal reservoir and makes reservoir cool down. This process can also lead to thermal damage on reservoir rock [8-13]. Hence, thermal cracking is a very common natural and engineering's phenomenon and widely applied to the exploitation of resources and energy.

Focusing on rock thermal cracking, much work has been done. Somerton conducted a research on thermal effect on sandstone corrosion and found that the rock permeability increased by $50 \%$ while the strength decreased by $50 \%$ after heat treatment [14]. Heard carried out investigations on thermal expansion coefficient and permeability of quartz monzonite and discovered that thermal expansion coefficient of the specimen increased with temperature rising and decreased at elevated confining stress [15]. Homand and Honpert found that new fractures were formed in the original intact granite and the fracture connectivity was 
improved with thermal effect [16]. They also found that the formed fracture length was dependent on the size and geometry of the crystals in granite. Chen discovered the thermal cracking threshold temperature in Westerly granite was $60^{\circ} \mathrm{C}-70^{\circ} \mathrm{C}$ through acoustic emission (later abbreviated as $\mathrm{AE})$ monitoring $[17,18]$. Zhang et al. found that the permeability of Carrara marble would be improved intensively at peak temperature up to $330^{\circ} \mathrm{C}-430^{\circ} \mathrm{C}$ [19]. Kemeny conducted experiments on Bolsa quartzite in Alisangna University and found that great changes took place in fracture density and permeability at $700^{\circ} \mathrm{C}-800^{\circ} \mathrm{C}$ [20]. Morrow conducted a permeability experiment of granite and concluded that the permeability decreased as temperature gradient increased [21]. Li et al. studied the changes of $M$ value, which meant the frequency and the amplitude distribution of $\mathrm{AE}$ are caused by rock temperature changes, in $\mathrm{AE}$ of thermal cracking of gabbro from Ji'nan and marble from Fangshan in China [22]. They found that intact rock had a higher $M$ value than fractured rock in a process that the temperature first rose up to $600^{\circ} \mathrm{C}$ and then back to room temperature (RT) at heating rates of $4.6^{\circ} \mathrm{C} / \mathrm{min}, 7^{\circ} \mathrm{C} / \mathrm{min}$, and $14^{\circ} \mathrm{C} / \mathrm{min}$, respectively. Kumari et al. performed experiment to study quenching effect on mechanical, microstructural, and flow properties of granite [23]. They found that increased porosity and crack density significantly enhanced the permeability of granite compared to the intact rock. However, with the increasing of normal stresses, permeability decreased nonlinearly and further, increasing temperature resulted in significant reductions in permeability of granite (approximately 95\% of reduction from room temperature to $300^{\circ} \mathrm{C}$ ) due to the thermally induced volumetric expansion which leads to enhancement of interlock effect.

Many laboratory studies on thermal cracking in rock have also appeared in the literature. However, they have predominantly been conducted on small samples of less than a few centimeters dimension. As we all know, sample size has significant influence on rock mechanical properties. The main reason is that big sample contains much more natural fissures than small sample. Zhao et al. studied the evolution of mechanical properties of large-scaled granite and found that thermally cracked granite exhibited typical features [24]. The natural fissures dominate the change of rock mechanical properties. Permeability in small sample, such as standard size of $50 \mathrm{~mm}$ in diameter and $100 \mathrm{~mm}$ long, mainly reflects the fluid flowing through pores. In fact, fluid flowing through fissures is the dominated factor affecting the extraction of geo-energy and georesource from geological reservoirs. Hence, permeability measurement of large-scaled sample can reflect the real fluid flowing in many geological engineering. Compared to small sample, permeability variation in large-scaled sample is more complex because it is the integrated result of pore and fissure variation while heating. In addition, many measurements on permeability with temperature were conducted after the heating temperature reduced room temperature. At present, no attempts are made to investigate thermal cracking and permeability of large-scale rocks at high temperature and triaxial pressure.
In this paper, we present $\mathrm{AE}$ monitoring and permeability measurement on large-scaled Luhui granite of $200 \mathrm{~mm}$ in diameter and $400 \mathrm{~mm}$ long at temperature up to $500^{\circ} \mathrm{C}$ and hydrostatic pressure of $25 \mathrm{MPa}$ with $600^{\circ} \mathrm{C} 20 \mathrm{MN}$ servo-controlled rock mechanics triaxial testing machine.

\section{Experimental Procedure}

2.1. Rock Samples. Two granite samples, named Luhui granite from Shandong, China, were selected for experiments on $\mathrm{AE}$ and permeability. Both samples were cored from large irregular shape blocks in a rock quarry in Pingyi, Shandong province. They were first tailored into cylindrical roughcast by stone processing machine and then lathed carefully into the test-required sample of $200 \mathrm{~mm}$ in diameter and $400 \mathrm{~mm}$ long.

The Luhui granite is composed of $28 \%$ quartz, $43 \%$ feldspar, and $30 \%$ others. The grain size of quartz is $0.6-0.7 \mathrm{~mm}$ and that of feldspar is $1-2 \mathrm{~mm}$. The initial porosity is $0.3 \%-0.55 \%$.

2.2. Experimental Setup. All experiments were performed on $600^{\circ} \mathrm{C} 20 \mathrm{MN}$ servo-controlled triaxial rock mechanics testing machine (Figure 1) developed by authors in China University of Mining \& Technology. The testing machine includes three parts: host loading system, auxiliary system for sample assembly, and measurement system. The host loading system can control and measure the temperature and pressure on samples and the deformation of samples. Both samples were assembled before testing on the auxiliary system, which is connected with host loading system by guide rail, but the two systems are independent. The measurement system consists of the measurement on permeability and the AE monitoring.

A sample was assembled in a high-temperature and high-pressure (later abbreviated as HTHP) vessel (Figure 2) before the test started. The confining pressure is transmitted by sodium chloride solid and the axial pressure is directly exerted to the end of the sample through a transmitted pressure steel cylinder. The axial and confining pressure can be loaded on the sample, respectively. As Bai and Wang pointed out that the confining pressure was uniform at room temperature for triaxial testing apparatus with solid confining medium [25], the deciding factor influencing axial pressure is the friction between solid confining medium and sample, and it can be almost eliminated by holding axial and confining pressure. Thus, the stresses applied to the sample are reliable. The deformation of the tested samples can be precisely measured by grating sensor with a precision of $0.005 \mathrm{~mm}$. Thermocouples are applied to measure the temperature of samples. The maximum axial and lateral loads are $10 \mathrm{MN}$, respectively, which can simulate a depth of about $10 \mathrm{~km}$ in the crust, and the maximum axial pressure on sample is $318 \mathrm{MPa}$ while the lateral pressure is $250 \mathrm{MPa}$. The size of samples is $200 \mathrm{~mm}$ in diameter and $400 \mathrm{~mm}$ long, approximately 64 times that of standard sample in volume. The maximum temperature of the testing machine is not 


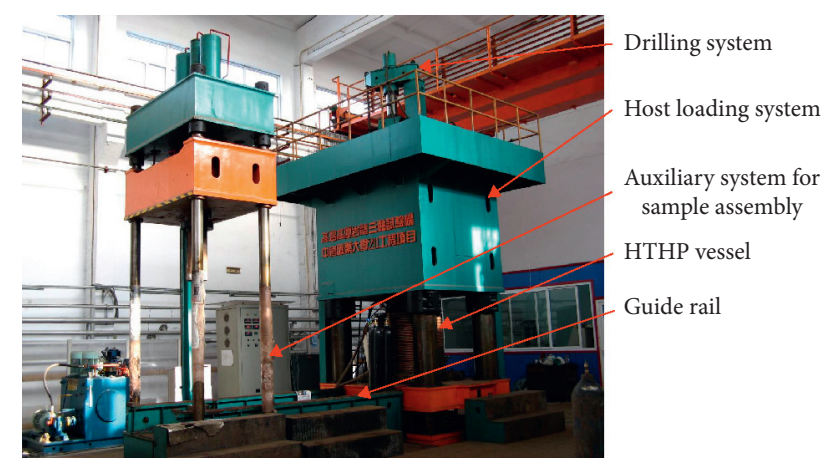

Figure 1: $600^{\circ} \mathrm{C} 20 \mathrm{MN}$ servo-controlled triaxial rock mechanics testing machine.

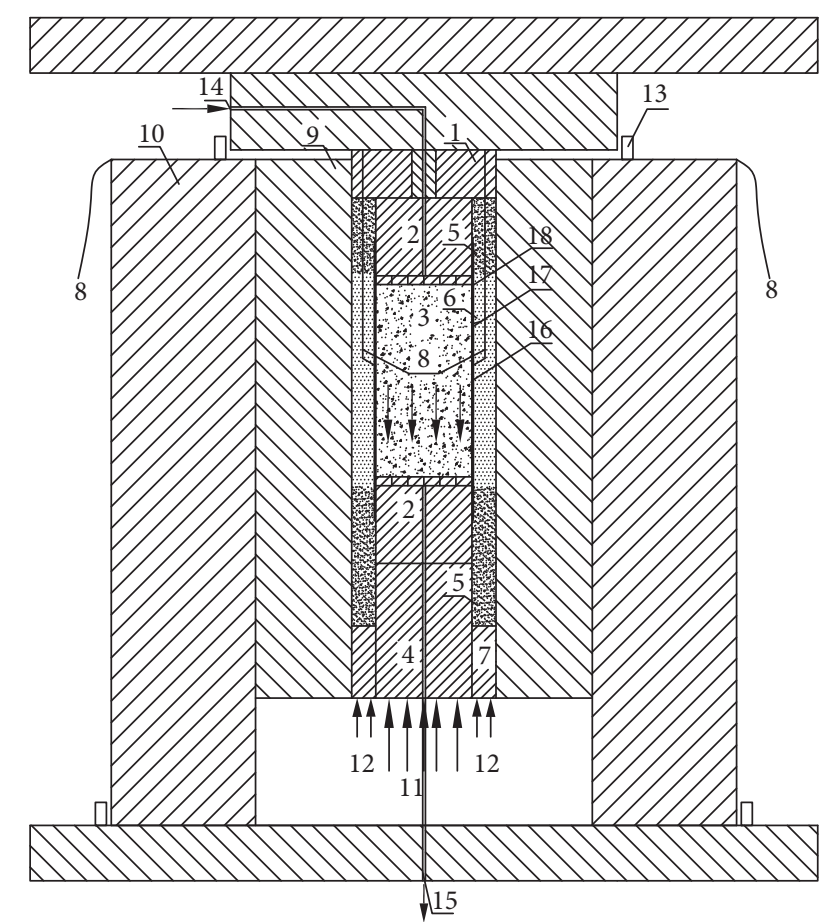

FIgURE 2: Schematic sample assembly in HTHP vessel. 1, cover; 2, secondary axial pressure pad; 3 , sample; 4 , main axial pressure pad; 5 , pyrophyllite powder; 6 , sodium chloride; 7 , confining pressure pad; 8 , thermocouple; 9 , pressure vessel interior layer; 10 , pressure vessel outside layer; 11, axial pressure; 12, confining pressure; 13 , $\mathrm{AE}$ receiver; 14, gas inlet; 15 , gas outlet; 16 , red copper sheet; 17 , phlogopite sheet; 18, heating resistor sheet.

less than $600^{\circ} \mathrm{C}$. The whole stiffness of the equipment is not less than $14.8 \times 10^{10} \mathrm{~N} / \mathrm{m}$.

2.3. Heat Treatment and AE Monitoring. The samples were jacketed in a red copper foil and were heated up to $500^{\circ} \mathrm{C}$ at a heating rate of $5^{\circ} \mathrm{C} / \mathrm{h}$ and triaxial pressure. A low rate of heating was used to ensure that cracking events of such large samples were the result of temperature alone and not due to thermal gradients $[18,26]$. Temperature was measured by four thermocouples whose resolution was about $0.1^{\circ} \mathrm{C}$. All thermocouples near the face of samples were imbedded in sodium chloride solid. Two thermocouples were imbedded at the ends of the sample and the other two were in the middle of the sample. Figure 2 shows schematically the experimental assembly.

Data from $\mathrm{AE}$ monitoring are used to relate the main cracking periods to temperature. When a crack initiates and grows, a volume of material is rapidly unloaded. This causes an elastic strain wave to propagate from the crack tip. This AE can provide important information about cracks.

Thermal cracking is monitored by recording the $\mathrm{AE}$ events. The parameters, such as AE counts and energy rate, are applied to describe $\mathrm{AE}$ activities. The $\mathrm{AE}$ signals propagate through the sample and are collected by a stainless-steel cylinder detector attached to the end of the HTHP vessel, and then the detector channels the signals along a waveguide to a PZT transducer fixed outside the vessel. The transducer is logged by a Disp-24 AE analyzer. Firstly, the prepared sample was loaded to the preestablished triaxial pressure (e.g., $25 \mathrm{MPa}$ ) after sample assembly. Then four AE sensors were strictly clamped by magnetic stand of the clock gauge on the top and bottom of the HTHP vessel. Vaseline was used to ensure the good coupling of sensors and the vessel. The confining and axial pressure of experiments were $25 \mathrm{MPa}$, respectively, which represented a burial depth of approximately $1 \mathrm{~km}$. Hydrostatic confining pressure was held constant for two hours by a microprocessor control system after loaded in order to eliminate the effect of natural crack closure and friction in HTHP vessel.

$\mathrm{AE}$ recorder real-timely detected crack signals through such parameters as $\mathrm{AE}$ counts, energy rate, event duration, and amplitude. In order to eliminate the interference of outside noise, we first started all the machines in the experiment before the test began, such as temperature controlling system, cooling water system, and loading system. Then the preamplified signals $(40 \mathrm{~dB})$ were bandpassed at $5-200 \mathrm{kHz}$ to reduce noise and were further amplified by a main amplifier to reach an overall gain whose value was set, respectively, according to the quantities of signals acquired by each channel. The threshold level of each channel was set until no signals were shown on the screen of Disp-24 AE analyzer and therefore we considered that outside noise had been eliminated. With the above experimental setting, multiple events which emitted low energy were probably not recorded. The recorded counts would therefore be somewhat lower than the number of actual countable events. However, this difference does not affect the general results reached in the present study. The sensor in the experiment could record $\mathrm{AE}$ signals 300 times per second. So the data were numerous. For convenience, we carried out a statistic on the AE events per second.

2.4. Permeability Measurement and Data Acquisition. All samples were sealed with a thin sheet of red copper which was covered with a $0.25 \mathrm{~mm}$ sheet of phlogopite (Figure 2). The heater band sleeve was applied to jacketing out of phlogopite. The entire assembly was then jacketed in a $0.25 \mathrm{~mm}$ sheet of phlogopite that could prevent sodium chloride from contact with heater band. 
The confining and axial pressure, $25 \mathrm{MPa}$, respectively, were held constant in the experiments. Measurements in permeability were conducted at room temperature (about $\left.15^{\circ} \mathrm{C}\right), 50^{\circ} \mathrm{C}, 100^{\circ} \mathrm{C}, 150^{\circ} \mathrm{C}, \ldots, 500^{\circ} \mathrm{C}$. Each goal temperature was held for at least 2 hours for heat equilibrium in the sample before measurement.

The steady state flow method was used for the present study. The pore pressure was held at $3 \mathrm{MPa}$ during measuring. The effective stress was $66 \mathrm{MPa}$. In order to only study the effect of temperature on permeability of granite, nitrogen gas was used as pore fluid so that any chemical effect could be minimized. The high-pressure nitrogen was controlled by a high-pressure valve and a high precision barometer. Figure 3 shows the flow chart of permeability measurement. Upstream gas from high-pressure nitrogen was injected into inlet hole and the injected gas pressure was maintained by a control valve, which was adjusted to give a reasonable flow and to preserve the condition of laminar flow in the sample. The downstream gas flowed out from the vent hole communicated with air. The gas flow was measured by a soap film flow-meter. Permeability was calculated from Darcy's Law in one dimension as follows:

$$
k=\frac{Q}{A} \frac{2 \mu L P_{\mathrm{atm}}}{\left(P_{i}^{2}-P_{\mathrm{atm}}^{2}\right)},
$$

where $k$ is the permeability (Darcy), $Q$ is the volumetric gas flow rate $\left(\mathrm{cm}^{3} / \mathrm{s}\right)$ experimentally measured at $P_{\text {atm }}$ (atmospheric pressure equal to $0.1 \mathrm{MPa}), P_{i}$ is the applied gas pressure (MPa), $\mu$ is the dynamic viscosity of nitrogen gas at goal temperature which was obtained from the tables of the Beijing Chemical Industrial Company Inc. [27], $L$ denotes the real-time length of sample $(\mathrm{cm})$ at each goal temperature (plus as thermal expansion and minus as compression), and $A$ is the cross-sectional area $\left(\mathrm{cm}^{2}\right)$.

\section{Results and Discussions}

3.1. Multistage Thermal Cracking Observed by Acoustic Emission. A low level of AE counts was produced below approximately $65^{\circ} \mathrm{C}$ (Figure 4 ). At $65^{\circ} \mathrm{C}$, there was a large burst of $\mathrm{AE}$ over a narrow range of temperature below $5^{\circ} \mathrm{C}$. It was followed by very few $\mathrm{AE}$ counts at $65^{\circ} \mathrm{C}-125^{\circ} \mathrm{C}$. There were other similar low $\mathrm{AE}$ levels at temperature ranges such as $175^{\circ} \mathrm{C}-200^{\circ} \mathrm{C}, \quad 325^{\circ} \mathrm{C}-400^{\circ} \mathrm{C}$, and $450^{\circ} \mathrm{C}-500^{\circ} \mathrm{C}$ in Figure 4(b). We could also observe $\mathrm{AE}$ count peaks with a broad temperature range occurring at $150^{\circ} \mathrm{C}, 200^{\circ} \mathrm{C}, 325^{\circ} \mathrm{C}$, and $450^{\circ} \mathrm{C}$. Note that the $\mathrm{AE}$ counts increased drastically only when the temperature exceeded $300^{\circ} \mathrm{C}$. The difference between sample 1 and sample 2 for AE counts at temperature below $300^{\circ} \mathrm{C}$ might be the result of sample diversity and/or difference of preset value in main amplifier.

The inner of heterogeneous rock appears as thermal stress as temperature changes under any mechanical state. As thermal stress exceeds the bearing capacity of inner grain and cement, thermal cracking appears internally in rock. The hypostasis of thermal cracking in rock is a multicrystal mineral consisting of diverse heterogeneous combo in mesostructure. The thermal expansion coefficients of various

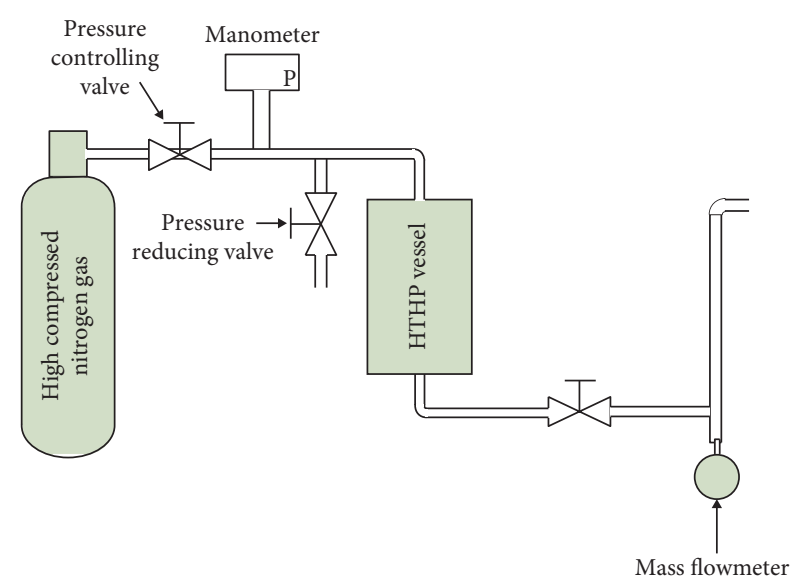

FIgURE 3: Flow chart of permeability measurement.

crystals and cement are completely different. Based on thermal elastic theory, thermal stress will occur in different crystals and cement, but thermal cracking may firstly appear in the binding material whose strength and melting point are lower than those of crystals. These results have been pointed out by Zhao in the investigation on mesostructure of Luhui granite with meso-CT [28].

Drastic AE response of thermal cracking inconsistently occurred at temperature range of $65^{\circ} \mathrm{C}-70^{\circ} \mathrm{C}, 125^{\circ} \mathrm{C}$, $225^{\circ} \mathrm{C}-250^{\circ} \mathrm{C}, 275^{\circ} \mathrm{C}-375^{\circ} \mathrm{C}, 425^{\circ} \mathrm{C}$, and $475^{\circ} \mathrm{C}-500^{\circ} \mathrm{C}$ for sample 1 and $65^{\circ} \mathrm{C}-70^{\circ} \mathrm{C}, 125^{\circ} \mathrm{C}-175^{\circ} \mathrm{C}, 250^{\circ} \mathrm{C}, 275^{\circ} \mathrm{C}-325^{\circ} \mathrm{C}$, and $400^{\circ} \mathrm{C}-475^{\circ} \mathrm{C}$ for sample 2 shown in Figure 4 , while quiet $\mathrm{AE}$ response occurred at other temperature ranges. So the characteristics of $\mathrm{AE}$ response that intensity and quietude occurred alternately were named as multistage. Before a microcrack formed, energy accumulation mainly took place, and low or even no AE signals appeared. Thermal cracking increasingly happened and large $\mathrm{AE}$ signals were shown when accumulative energy was sufficient for microcrack forming and growing at some temperature ranges. The other reason for multistage of $\mathrm{AE}$ is that diverse mineral grains in granite have different thermal expansion coefficients and new forming microcracks need various energy accumulations in grain boundary or inner grain.

\subsection{Multipeak Permeability in Thermally Cracked Granite.} The permeability of the samples commenced to increase at room temperature (Figure 4). It reached the first peak at the temperature of $100^{\circ} \mathrm{C}$ to $150^{\circ} \mathrm{C}$. It was then followed by a decrease. The temperature range of permeability that decreased in the two samples was different for the reason of diversity in $\mathrm{AE}$ counts. The range for sample 1 was from about $100^{\circ} \mathrm{C}$ to $300^{\circ} \mathrm{C}$ owing to the low $\mathrm{AE}$ level at temperature from the first peak temperature to about $225^{\circ} \mathrm{C}$. But it was only from $150^{\circ} \mathrm{C}$ to $200^{\circ} \mathrm{C}$ for sample 2 due to the high $\mathrm{AE}$ counts at about $200^{\circ} \mathrm{C}$ shown in Figure 4 . So the permeability of sample 2 stopped decreasing and tended to increase after $200^{\circ} \mathrm{C}$. We also observed that it began to increase sharply at $300^{\circ} \mathrm{C}$ and the second peak appeared at $400^{\circ} \mathrm{C}-450^{\circ} \mathrm{C}$. The permeability decreased again after peak temperature. 


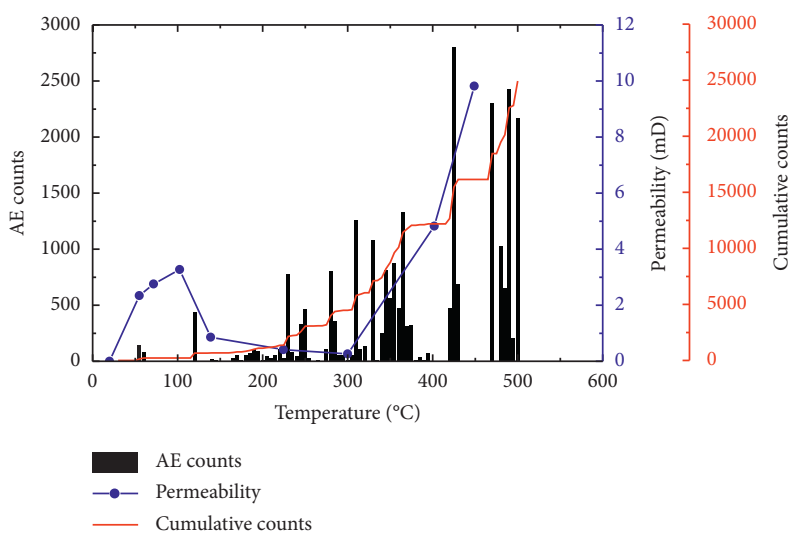

(a)

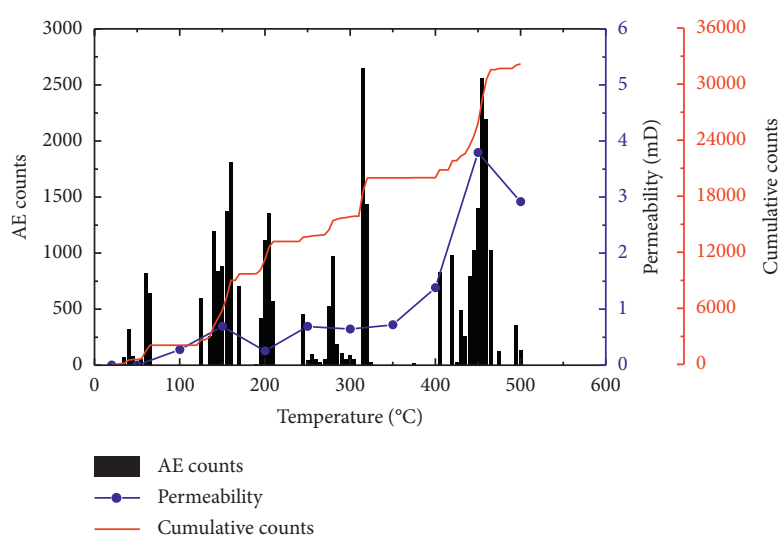

(b)

Figure 4: AE counts and permeability of two samples at high temperature and 3D stress. (a) Sample 1. (b) Sample 2.

The permeability showed multipeak in granite due to multistage of thermal cracking at elevated temperature in Figure 4 . The permeability increased gradually at temperature up to $150^{\circ} \mathrm{C}$. It was followed by a maximum value at temperature range from $100^{\circ} \mathrm{C}$ to $150^{\circ} \mathrm{C}$. Then the permeability decreased to the minimum value which was still higher than the initial value. The permeability began to increase steeply at $300^{\circ} \mathrm{C}$ and then the second peak value was almost $450^{\circ} \mathrm{C}$. It still showed a decrease again after $450^{\circ} \mathrm{C}$ which was higher than the former minimum. There were two peaks at our testing temperature ranges.

The mechanism of permeability change may be interpreted by the evolution of microcracks in Figure 5. The microcracks were observed through MPV-SP microphotometer and the methods and procedures for observation were introduced by Feng et al. [10]. The counts of microcracks (length $>5 \mu \mathrm{m}$ and length $>10 \mu \mathrm{m}$ ) began to increase at room temperature and the counts (length $>5 \mu \mathrm{m}$ ) reached maximum at temperature between $100^{\circ} \mathrm{C}$ and $150^{\circ} \mathrm{C}$. It was consistent with the permeability change. So the increase of counts in microcrack was the reason for permeability increase. After the maximum, the counts reduced in the microcrack with length above $5 \mu \mathrm{m}$ and slowly increased in that with the length above $10 \mu \mathrm{m}$. But they both decreased to the minimum at the temperature up to almost $200^{\circ} \mathrm{C}$. Thermal expansion may be the result of decrease in count of microcracks. Thermal expansion may induce new microcracks whose lengths are less than $5 \mu \mathrm{m}$ and these new microcracks may result in the closure of formed microcracks such as those whose lengths are larger than $5 \mu \mathrm{m}$ and $10 \mu \mathrm{m}$. So the permeability also reduces to minimum due to closure of influent flow channels. The counts increased again with temperature rising above $200^{\circ} \mathrm{C}$. But the permeability only increased a little (Figure 4(b)). When the temperature exceeded $300^{\circ} \mathrm{C}$, the counts of microcracks reduced again and numerous new microcracks might be induced by thermal expansion once more. Many new microcracks connect with each other and those which have been formed. Then the microcrack net is established and so the permeability increases sharply after $300^{\circ} \mathrm{C}$. Particularly, dramatic thermal cracking occurred at $450^{\circ} \mathrm{C}$ seen in Figure 4 . A great

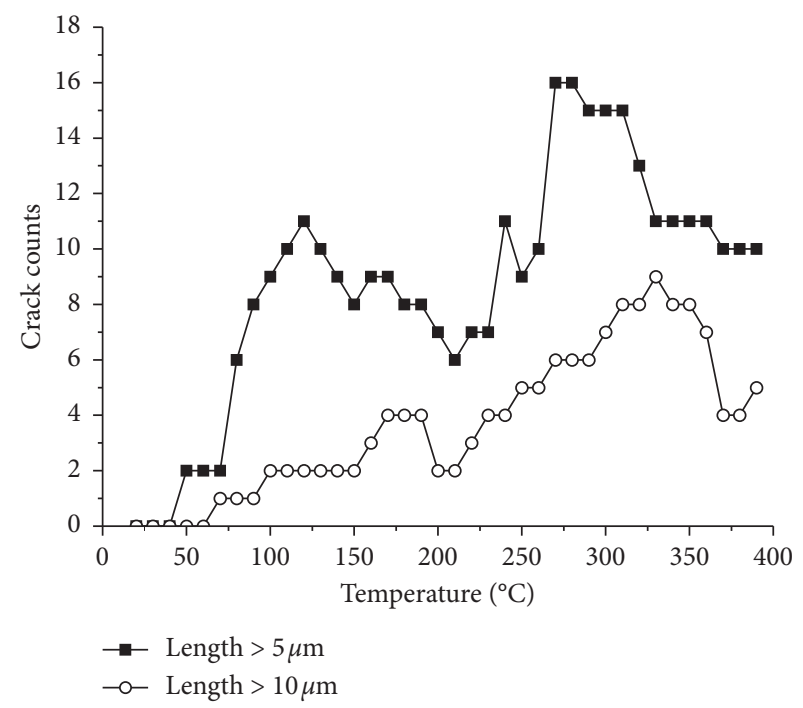

FIGURE 5: Variation of microcrack counts at elevated temperature $[10,29]$.

number of thermally induced microcracks were initiated and interconnected. The granite was damaged a lot and softened. Thermally induced microcracks were compressed to close and reduced the permeability. The reason for the decrease in permeability after $450^{\circ} \mathrm{C}$ may be that the large formed cracks are closed because of the confining pressure and new microcracks.

Accumulation of $\mathrm{AE}$ counts can represent energy emission of thermally cracked granite. Generally, more energy emission will induce more microcracks in granite. We define a parameter which describes the ratio $(e)$ of permeability at each temperature $\left(k_{T}\right)$ to permeability maximum value $\left(k_{\max }\right)$ at $450^{\circ} \mathrm{C}$, seen in equation (2).

$$
e=\frac{k_{T}}{k_{\max }}
$$

The ratio can approximately represent the proportion of microcracks induced by different temperature in total microcrack quantity at up to $450^{\circ} \mathrm{C}$. We define the other one parameter $(f)$ to describe the ratio of cumulative counts $\left(c_{T}\right)$ 
at each temperature to total counts $\left(c_{\text {to }}\right)$ at up to $450^{\circ} \mathrm{C}$, seen in equation (3). The relationship between cumulative counts and permeability can be expressed by both parameters $e$ and $f$, shown in Figure 6.

$$
f=\frac{c_{T}}{c_{\text {to }}} \text {. }
$$

The permeability ratio was very high below $100^{\circ} \mathrm{C}$ in sample 1 while cumulative counts ratio was very low, pointed by an arrow in Figure 6. This indicated that permeability increment was induced by other factors in addition to thermal cracking at low temperature. The factor may be water loss in granite. When the temperature exceeded $150^{\circ} \mathrm{C}$, the permeability ratio increased with cumulative counts ratio rising. The relationship could be approximately expressed by linear function in equation (4) with correlation coefficient of 0.83 .

$$
e=0.78 f-9.65
$$

3.3. Lagging Change in Permeability. That the changes in permeability lag behind thermal cracking changes is found in this study. The first drastic period of thermal cracking based on AE counts in granite started at around $125^{\circ} \mathrm{C}$ and the first peak permeability began at approximately $150^{\circ} \mathrm{C}$ in Figure 4(b). The second peak permeability occurred at $450^{\circ} \mathrm{C}$ while the second drastic period of thermal cracking happened at almost $425^{\circ} \mathrm{C}$. The temperature is higher for permeability peak than that for AE counts peak. We can observe from Figure 5 that the peak temperature of crack counts is higher in large microcracks (length $>10 \mu \mathrm{m}$ ) than that in small microcracks (length $>5 \mu \mathrm{m}$ ). AE count peak even may be induced by small microcracks. But permeability peak must be subjected to large microcracks. Thermally induced cracks go through stages of initiation, propagation, and connection and then form large cracks which are the channels for influent flow. So the temperature of drastic AE activities is lower than that of permeability peak.

3.4. Comparison and Practical Meaning. Real-time permeability in rock is quite difficult to measure at high temperature and triaxial stresses due to sealing. Recently, in order to study thermal cracking induced by heating sample, a great number of studies with heating-cooling cycles of sample were performed to obtain permeability variation at different temperatures. Figure 7 shows permeability evolution with temperature at both real-time and heatingcooling treatment conditions.

The ratio $\left(k_{T} / k_{0}\right)$ in the longitudinal axis of Figure 7 denotes the permeability at nominal temperature over that at room temperature. The permeability of granite treated by heating-cooling exhibited monotonous increasing. The realtime heated sample 2 in this study showed nonmonotonic change in permeability. Permeability of slow-cooling treated granite samples started to drastically increase at approximately $500^{\circ} \mathrm{C}$ in $[26,30-32]$. For fast-cooling treated samples, permeability significantly increased at about $400^{\circ} \mathrm{C}$ seen

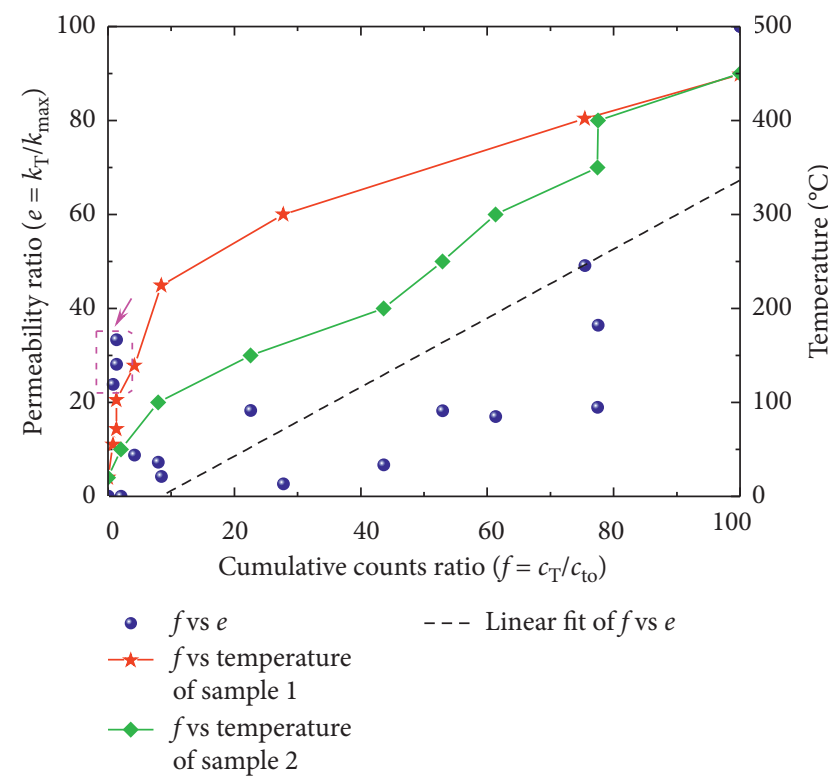

FIgURE 6: Relationship between cumulative counts and permeability of samples.

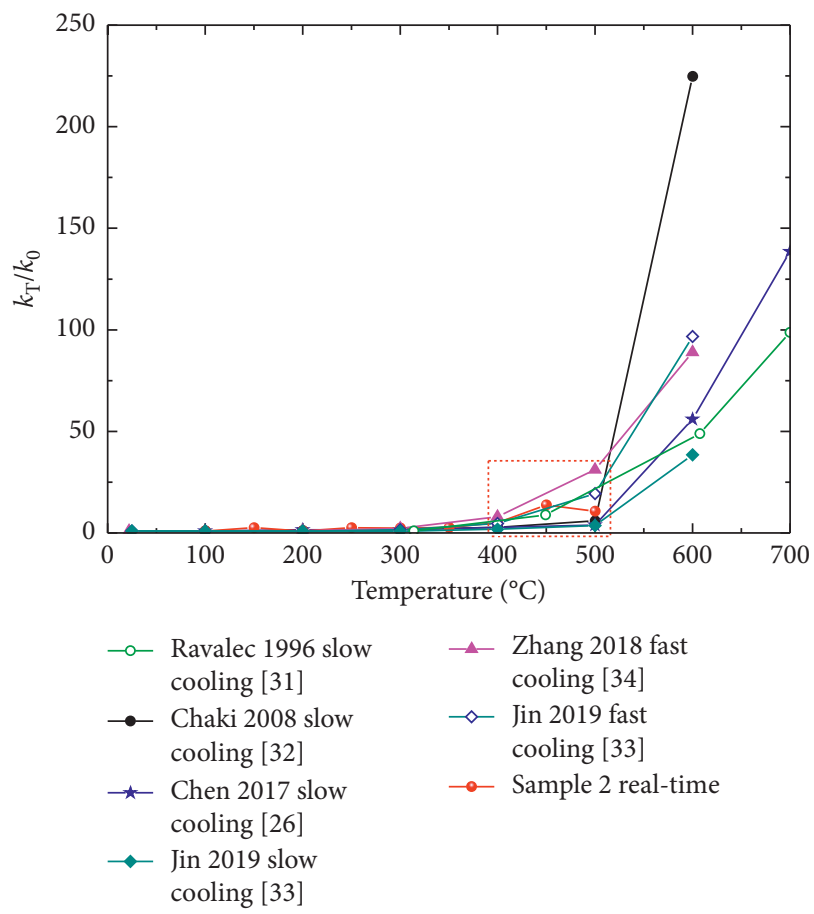

FIgURE 7: Comparison to permeability between real-time and heating-cooling treatment.

in $[32,33]$. This indicated that cooling rate had significant impact on heated samples. However, the real-time heated sample experienced a big increment at about $300^{\circ} \mathrm{C}$. The difference may be attributed to stress effect. While samples were heated at triaxial stresses state, there exist thermal and mechanical coupling effect in sample. The coupled effect can facilitate damage in rock to easily occur at high temperatures. The results considering the thermal and mechanical 
coupled effect on permeability of rock are more realistic in some engineering such as extraction of hot dry rock geothermal energy.

The results in this paper may be applied to the engineering such as hot dry rock and nuclear waste disposal. If the rock temperature of energy reservoir exceeds $300^{\circ} \mathrm{C}$, the artificial reservoir will be easily constructed because the rock permeability increases sharply after $300^{\circ} \mathrm{C}$. When the surrounding rock temperature of nuclear waste deposit is lower than $300^{\circ} \mathrm{C}$, the disposal is relatively safe. But once the temperature is higher than $300^{\circ} \mathrm{C}$, the cracking of surrounding rock will be strengthened. The groundwater will easily flow in the surrounding rock and then be polluted by the radioactive nuclide.

\section{Conclusions}

We have studied in detail thermal cracking and permeability change in large-scaled granite with $200 \mathrm{~mm}$ in diameter and $400 \mathrm{~mm}$ long at temperature up to $500^{\circ} \mathrm{C}$ and hydrostatic pressure of $25 \mathrm{MPa}$, using $\mathrm{AE}$ monitoring technology and steady state method. The remarkable conclusions can be drawn as follows.

(1) AE monitoring indicates that thermal cracking in large-scaled granite is discontinuous and multistage. These features correspond to energy accumulation and emission in the formation process of thermally induced microcracks during heating.

(2) The permeability induced by thermal cracking does not vary monotonously with temperature rising due to multistage of thermal cracking. The permeability has two peaks at temperature of $100^{\circ} \mathrm{C} \sim 150^{\circ} \mathrm{C}$ and around $450^{\circ} \mathrm{C}$.

(3) The temperature of each permeability peak lags behind that of the drastic AE period. Permeability change is consistent with cumulative AE counts. A linear function can describe the relationship between permeability and cumulative counts.

\section{Data Availability}

The data used to support the findings of this study are available from the corresponding author upon request.

\section{Conflicts of Interest}

The authors declare no conflicts of interest.

\section{Acknowledgments}

The authors are grateful to Fu-ke Dong, Jin-wen $\mathrm{Wu}$, and Ning Zhang for their assistance with the experiments. This research was funded by a research project supported by Shanxi Scholarship Council of China (2019), National Natural Science Foundation of China, grant number U1810104, and the Program for the Outstanding Innovative Teams of Higher Learning Institutions of Shanxi.

\section{References}

[1] M. H. Doranehgard and M. Siavashi, "The effect of temperature dependent relative permeability on heavy oil recovery during hot water injection process using streamline-based simulation," Applied Thermal Engineering, vol. 129, pp. 106116, 2018

[2] F. Torabi, N. Mosavat, and O. Zarivnyy, "Predicting heavy oil/ water relative permeability using modified Corey-based correlations," Fuel, vol. 163, pp. 196-204, 2016.

[3] M. Akhlaghinia, F. Torabi, and C. W. Chan, "Effect of temperature on two-Phase relative permeabilities of heavy oil, water, carbon dioxide, and methane determined by displacement technique," Energy \& Fuels, vol. 27, no. 3, pp. 1185-1193, 2013.

[4] A. W. Bhutto, A. A. Bazmi, and G. Zahedi, "Underground coal gasification: from fundamentals to applications," Progress in Energy and Combustion Science, vol. 39, no. 1, pp. 189-214, 2013.

[5] O. Solcova, K. Soukup, J. Rogut et al., "Gas transport through porous strata from underground reaction source; the influence of the gas kind, temperature and transport-pore size," Fuel Processing Technology, vol. 90, pp. 1495-1501, 2009.

[6] M. S. Blinderman, "Global development of commercial underground coal gasification," IOP Conference Series Earth and Environmental Science, vol. 76, pp. 1-6, 2017.

[7] C. D. Martin and R. Christiansson, "Estimating the potential for spalling around a deep nuclear waste repository in crystalline rock," International Journal of Rock Mechanics and Mining Sciences, vol. 46, no. 2, pp. 219-228, 2009.

[8] Z. Feng, Y. Zhao, A. Zhou, and N. Zhang, "Development program of hot dry rock geothermal resource in the Yangbajing Basin of China," Renewable Energy, vol. 39, no. 1, pp. 490-495, 2012.

[9] Y. Zhao, Z. Feng, Y. Zhao, and Z. Wan, "Experimental investigation on thermal cracking, permeability under HTHP and application for geothermal mining of HDR," Energy, vol. 132, pp. 305-314, 2017.

[10] Z. Feng, Y. Zhao, Y. Zhang, and Z. Wan, "Real-time permeability evolution of thermally cracked granite at triaxial stresses," Applied Thermal Engineering, vol. 133, pp. 194-200, 2018.

[11] Z. Zhong, D. Huang, Y. F. Zhang et al., "Experimental study on the effects of unloading normal stress on shear mechanical behaviour of sandstone containing a parallel fissure pair," Rock Mechanics and Rock Engineering, 2019.

[12] D. Huang, Y. Q. Li, Y. X. Song, Q. Xu, and X. J. Pei, "Insights into the catastrophic Xinmo rock avalanche in Maoxian county, China: combined effects of historical earthquakes and landslide amplification," Engineering Geology, vol. 258, p. 105158, 2019.

[13] D. M. Gu, D. Huang, H. L. Liu, W. G. Zhang, and X. C. Gao, "A DEM-based approach for modeling the evolution process of seepage-induced erosion in clayey sand," Acta Geotechnica, vol. 14, no. 6, pp. 1629-1641, 2019.

[14] W. H. Somerton and V. S. Gupta, "Role of fluxing agents in thermal alteration of sandstones," Journal of Petroleum Technology, vol. 35, pp. 1039-1046, 1965.

[15] H. C. Heard, "Thermal expansion and inferred permeability of climax quartz monzonite to $300^{\circ} \mathrm{C}$ and $27.6 \mathrm{MPa}$," International Journal of Rock Mechanics and Mining Sciences \& Geomechanics Abstracts, vol. 17, no. 5, pp. 289-296, 1980.

[16] E. F. Homand and R. Honpert, "Thermally induced micro cracking in granites: characterization and analysis," 
International Journal of Rock Mechanics and Mining Sciences \& Geomechanics Abstracts, vol. 26, pp. 124-134, 1989.

[17] Y. Chen, "Experimental research of rock thermal cracking," Chinese Science Bulletin, vol. 44, pp. 880-883, 1999.

[18] Y. Chen and C. Y. Wang, "Thermally induced acoustic emission in westerly granite," Geophysical Research Letter, vol. 7, pp. 1089-1092, 1980.

[19] S. Zhang, M. S. Paterson, and S. F. Cox, "Microcrack growth and healing in deformed calcite aggregates," Tectonophysics, vol. 335 , no. $1-2$, pp. 17-36, 2001.

[20] J. Kemeny and Z. Zomeni, "A comparison of eight methods for measuring grain and boundary cracking in heated quartzite samples," International Journal of Rock Mechanics and Mining Sciences, vol. 35, no. 4-5, pp. 506-507, 1998.

[21] C. Morrow, D. Lockner, D. Moore, and J. Byerlee, "Permeability of granite in a temperature gradient," Journal of Geophysical Research: Solid Earth, vol. 86, no. B4, pp. 3002-3008, 1981.

[22] J. H. Li, X. H. Liu, and J. S. Hao, "Temperature effect on the elastic wave velocity and acoustic emision of rocks samples," Acta Seismologica Sinica, vol. 8, pp. 293-300, 1986.

[23] W. G. P. Kumari, P. G. Ranjith, M. S. A. Perera, and B. K. Chen, "Experimental investigation of quenching effect on mechanical, microstructural and flow characteristics of reservoir rocks: thermal stimulation method for geothermal energy extraction," Journal of Petroleum Science and Engineering, vol. 162, pp. 419-433, 2018.

[24] Y. S. Zhao, Z. J. Wan, Z. J. Feng, Z. H. Xu, and W. G. Liang, "Evolution of mechanical properties of granite at high temperature and high pressure," Geomechanics and Geophysics for Geo-Energy and Geo-Resources, vol. 3, no. 2, pp. 199-210, 2017.

[25] T. X. Bai and S. Z. Wang, "Numerical modeling of stress distribution in rock specimen under triaxial compression with solid confining medium," Chinese Journal of Rock Mechanics and Engineering, vol. 9, pp. 154-163, 1990.

[26] S. Chen, C. Yang, and G. Wang, "Evolution of thermal damage and permeability of Beishan granite," Applied Thermal Engineering, vol. 110, pp. 1533-1542, 2017.

[27] Beijing Chemical Industrial Company Inc, Cryogenic Handbook, pp. 216-217, Chemical Industry Press, Beijing, China, 1979.

[28] Y. S. Zhao, Q. R. Meng, T. H. Kang et al., "Micro-CT experimental technology and meso investigation on thermal fracturing characte- ristics of granite," Chinese Journal Rock Mechanics and Engineering, vol. 27, pp. 28-34, 2008.

[29] Y. Zhang, X. Zhang, and Y. S. Zhao, "Process of sandstone thermal cracking," Chinese Journal of Geophysics, vol. 48, pp. 656-659, 2005.

[30] M. L. Ravalec, M. Darot, T. Reuschlé et al., “Transport properties and microstructural characteristics of a thermally cracked mylonite," Pure and Applied Geophysics, vol. 146, pp. 207-227, 1996.

[31] S. Chaki, M. Takarli, and W. P. Agbodjan, "Influence of thermal damage on physical properties of a granite rock: porosity, permeability and ultrasonic wave evolutions," Construction and Building Materials, vol. 22, no. 7, pp. 1456-1461, 2008.

[32] P. Jin, Y. Hu, J. Shao, G. Zhao, X. Zhu, and C. Li, "Influence of different thermal cycling treatments on the physical, mechanical and transport properties of granite," Geothermics, vol. 78, pp. 118-128, 2019.

[33] F. Zhang, J. Zhao, D. Hu, F. Skoczylas, and J. Shao, "Laboratory investigation on physical and mechanical properties of granite after heating and water-cooling treatment," Rock Mechanics and Rock Engineering, vol. 51, no. 3, pp. 677-694, 2018. 